\title{
Electrochemical Behaviour of Passive Films Formed on Inconels 600 and 690
}

\author{
Diadioly Gassama, Sana Faty \\ Faculty of Science and Technology, University of Thies, Thies, Senegal \\ Email: gassamadiadiol@gmail.com, safaty_52@hotmail.com
}

Received 21 November 2015; accepted 5 December 2015; published 10 December 2015

Copyright (C) 2015 by authors and OALib.

This work is licensed under the Creative Commons Attribution International License (CC BY). http://creativecommons.org/licenses/by/4.0/

(C) (i) Open Access

\begin{abstract}
We have verified through an electrochemical technique (capacity, impedance and photo-electrochemical measurement) and also through an analytic technique of auger spectrometry that passive films formed on inconels 600 and 690 are comprised of two layers. This has led us to establish precise links between the chemical composition of passive films formed on inconels and their electrochemical properties. The results obtained at different frequencies show the existence of two areas. The passive oxide formed on alloy 600 is richer in iron oxide than the one formed on alloy 690.
\end{abstract}

\section{Keywords}

Inconel, Passive Films, Capacity, Impedance, Photocurrent, Semi-Conductivity

Subject Areas: Electrochemistry, Material Experiment

\section{Introduction}

In conel 600 is used in the nuclear for its resistance to hot oxidation but it tends to be replaced by inconel 690 for sensitivity reasons in high temperature water.

The economic and technical importance of passivation is the cause of a considerable number of researches on passive films. These researches have been for many years of potential-static or potential-dynamic type or impedance measurement, and then come the analytic studies supported by the development of surfacetechnique.

The specific or joint action of chromium, iron and nickel oxides as far as electronic structure is concerned, is far from being perfectly known. The published works reveal more the properties of iron oxide layers keeping the interface with the electrolyte. In fact, these ironoxides are the external part of passive films formed on stainless steels [1]-[5].

This work concerns the electronic structure of passive films formed on two families of nickel-based alloy of inconel type: 600 (Ni-17\%Cr-8\%Fe) and 690 (Ni-29\%Cr-8\%Fe). 
The study is conducted using impedance measurements, capacity and photo electrochemistry. It aims at determining the semiconducting nature of the passive films on these two inconels.

\section{Experimental Conditions}

The formation of passive films formed on the inconels was carried out in an autoclave, in the middle of the primary type of pressurized water reactors (1000 ppm of Bore, 2 ppm de Lithium, under 3 bars of dihydrogen and at $350^{\circ} \mathrm{C}$ ) test tubes of $2 \times 3 \mathrm{~cm}$ that have been mechanically polished up to the diamond. The treatment of the oxidation in autoclave lasted 2000 hours. The electrochemical study is made using plaques of about $1 \mathrm{~cm}^{2}$ of surface area wrapped up in epoxy and/or acrylic type resin.

The electrochemical study is performed using platelets from about $1 \mathrm{~cm}^{2}$ to cut out from steel plates supplied by CNRS France, coated in epoxy resins and/or acrylic acid, thereby forming a working electrode. The surface of this electrode was mechanically polished with abrasive paper of decreasing size (400-600-1200) with a finish to alumina $2 \mu$. The electrode is then rinsed with distilled water, cleaned ultrasonically and dried in air. Once in the cell, the sample (working electrode) is cathodically polarized for 5 minutes under the action of a current of approximately $5 \mathrm{~mA} \cdot \mathrm{cm}^{-2}$ to reduce oxides formed in air. This cathode reduction is followed as soon as possible with a polarization film forming potential. The nature of the resulting film is intimately linked with the training requirements (potential, time and $\mathrm{pH}$ ).

All the experiences took place in the ambient temperature under non-stop paddling of nitrogen to deaerate the solution. The used electrolyte is the solution tetra borate-acid boric of chemical composition: $\mathrm{H}_{3} \mathrm{BO}_{3}(0.05 \mathrm{M})+$ $\mathrm{Na}_{2} \mathrm{~B}_{4} \mathrm{O}_{7} .10 \mathrm{H}_{2} \mathrm{O}(0.075 \mathrm{M})$ (solution tampon de $\mathrm{pH}=9.2$ ).

The measurements are performed from the potential of formation. The impedance measurements made on electrochemical systems required the application of a low frequency excitement signal. These measurements are made with a potentiostat (273EGG/PAR) which permits the polarization of the electrode of work and the detection synchronous double phase lock-in (Brook deal 5208 EGG/PAR). The principle consists in modulating the potential of the electrode (potential of formation of the films) by an alternative signal of amplitude $10 \mathrm{mV}$. Capacity measurements are conducted with the same experimental principle as impedance measurements with a difference that lies in the need of making fixed frequency measurements by varying the potential. A 378 AC impedance software turning on PC XT controls the system. An Epson 80 printer permits to display and to represent the results either on digital form or on graphic form.

To obtain the profile of the thin films around $30 \AA$ thick, we used the auger spectrometry. We used a photoelectrochemical cell for the electro-chemical measurements. The sample constitutes the electrode of work, the counter electrode is a platinum thread with a geometrical surface of $1 \mathrm{~cm}^{2}$ and the electrode of reference is the saturated calomel electrode (sce). The solutions are prepared from PROLABO quality RP Norma-pure dissolved inbi-permutated water.

The three-electrode photo electrochemical cell with a quartz window insuring the passage of the luminous flux is set to a positioning support. This support has micrometrical screws allowing its vertical moving (YZ) perpendicular to the optic bench. The translation in an $\mathrm{X}$ axis is assured by the support of the fixation of the optic bench. Only the photo detector is set to the second optic bench perpendicular to the first because of the division at $90^{\circ}$ of the luminous beam previously described.

For the determination of the photocurrent in relation to the wavelength, it is an engine controlled step by step by a piloting module (spectra link) which allows the variation of the wavelength and a potential-stat (273 EGG/ PAR) that maintains the polarization of the sample. At fixed wavelength, the scanning in potential is made by means of potential-stat. We have worked at low frequency of modulation $(19 \mathrm{~Hz})$. The incidence of the luminous flux at the level of the sample is normal. The piloting of equipment as well as the analysis and the acquisition of data is done with a microcomputer PC 386.

The photo electrochemical apparatus that we have used is composed of:

- Light source: It is supplied by a Xenon Arc lamp (150 W) of a spectral distribution varying with the wavelength.

- Focusing Lens: It focuses the light beam on the entrance slit of the monochromator.

- Monochromator: Jobin-Yvon kind Czerny-Turner of a focal length of $250 \mathrm{~mm}$ input and output slots are set to $2 \mathrm{~mm}$, which gives a bandwidth of $13 \mathrm{~mm}$. The explored spectral range is from $300 \mathrm{~mm}$ to $750 \mathrm{~mm}$. Above $450 \mathrm{~mm}$, the use of a "long pass" filter eliminates the second harmonic UV. Its optimization inorder 
to achieve good resolution and high brightness should be done by:

- Choosing the best compromise between the width of the input and output slots.

- The choice of networks according to the desired spectral range. The network (a) blazed to $500 \mathrm{~mm}$ can be used in the visible range (400 - $700 \mathrm{~mm}$ ), whereas the network (b) blazed to $250 \mathrm{~mm}$ is more suitable for ultraviolet studies.

- Light modulator (Chopper): (10 to $220 \mathrm{~Hz}$ ) driven by the internal oscillator of the synchronous detection (lock-in Brookdeal 5208).

- Beam splitter: Is a device provided with a quartz plate, allowing the deflection of a portion (10\%) of $90^{\circ}$ to the light beam, and two focusing lenses beams obtained (after division) on the sample and a silicon photo detector. This method allows to know in real time and for each wavelength flux incident on the sample. The determination of the photon flux incident on the photo detector is made using a current-converter/voltage amplifier and a synchronous detection (lock-in Brookdeal 9503). It can be traced back, after a double marking, the photon flux incident on the sample. Indeed, the blade of the transmission coefficient of the beam splitter and the output of the photodetector will vary depending on the wavelength.

Table 1 shows the chemical composition of two nickel-basedalloys 600 and 690.

\section{Results}

\subsection{Auger Spectrometry}

The profiles of in-depth composition of passive films at $2.0 \mathrm{~V}$ on the two nuances of inconels 600 and 690 are represented in Figure 1. The atomic density of internal region in contact with the alloy is constituted essentially with oxide of chrome, while the external region of the film is mainly composed with oxide of nickel. The oxide of iron in low quantity is either in the internal region in the case of the passive films formed in the inconel 600 or in the external region if it is the film formed in the inconel 690. We remark that the interface between the two regions (external and internal) is not abrupt. The comparison of the films formed on the two inconels shows a quantitative difference concerning the thickness and the atomic density of the oxides. This indicates that the natures of the films are intimately linked to the chemical composition of the alloy. On the inconel 690 richer in chrome, there is a film mostly composed of oxide of chrome. Even though nickel is a basic element of this alloy, its oxide present inside the external region of the film is represented by a very thin thickness ( 2 to 3 mono-stratum).

On the other hand, concerning the inconel $600(15 \% \mathrm{Cr})$ both regions have practically the same thickness. Concerning the atomic density, the difference registered between the nickel and the chrome oxides is practically the same for both alloys. Figure 1 shows that inside the internal part of the film the number of chrome atoms in the oxide is practically equal to $8.7 \mathrm{at} \cdot \mathrm{nm}^{-2}$. This value corresponds to that of type $\mathrm{Cr}_{2} \mathrm{O}_{3}$. The number of nickel atoms in the oxide external position is about $6 \mathrm{at} \cdot \mathrm{nm}^{-2}$.

\subsection{Potential Dynamic Measurement}

In our study, the line of the current/potential curves is made at the speed of $1 \mathrm{mV} / \mathrm{s}$ from the cathode potentials to the anode potentials. In order to lessen the oxides gathered in the air, a pre-polarization cathode $\left(5 \mathrm{~mA} \cdot \mathrm{cm}^{-2}\right)$ preceded the potential dynamic study for about 5 minutes (values are given in relation to the calomel).

To determinate the role of the iron in the nickel-based materials; we proceeded to the preparation by fusion to plasma of a series of pure alloys. The potential-dynamic study led on the binaries $\mathrm{Ni}-15 \% \mathrm{Cr}$, Ni-30\%Cr on one hand and the binaries $\mathrm{Ni}-15 \% \mathrm{Cr}-8 \% \mathrm{Fe}, \mathrm{Ni}-30 \% \mathrm{Cr}-8 \% \mathrm{Fe}$ on the other hand allowed us to put in evidence the influence of the addition of the iron. It is suitable to make the remark that the last two alloys represent the versions of high purity of alloy 600 and 690. In the analysis Figure 2 where we represent the curves of polarization obtained in the same experimental conditions on the four alloys, many points are to be underlined.

Table 1. Chemical composition of the inconels 600 and 690 (wt\%).

\begin{tabular}{ccccccccc}
\hline Element & Ni & Cr & Fe & Mn & Cu & Si & C & 0.50 \\
Inconel 600 & Majority & 17.0 & 8.0 & 1.0 & 0.50 & 0.15 \\
Inconel 690 & Majority & 29.0 & 7.8 & 0.5 & 0.5 & 0.5 & 0.05 \\
\hline
\end{tabular}



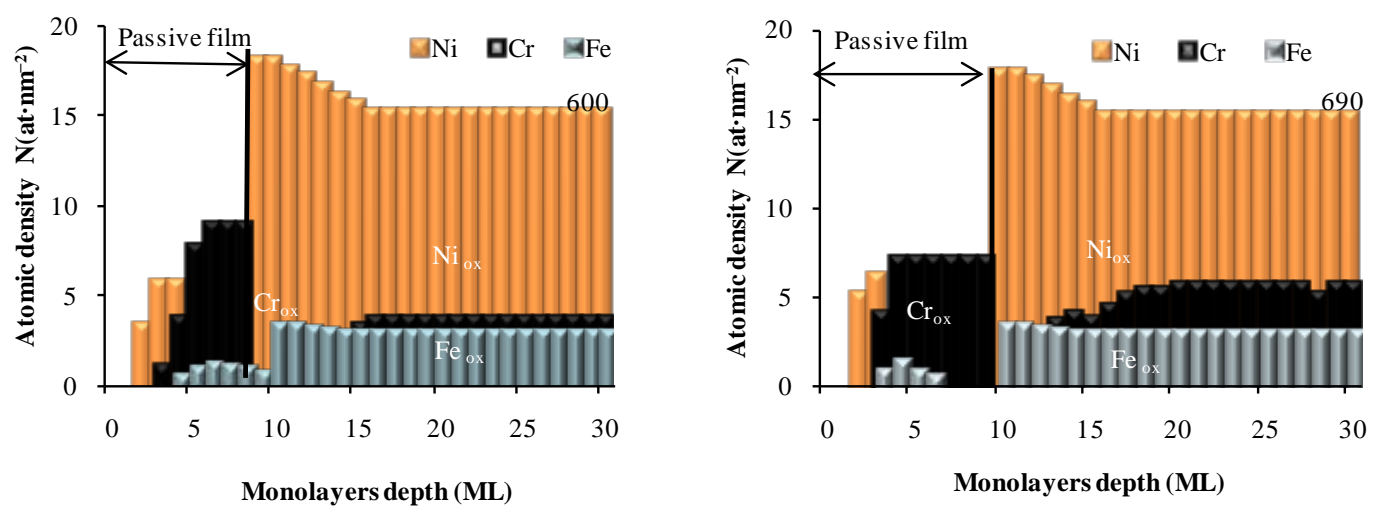

Figure 1. Profiles of chemical composition of inconels 600 and 690.

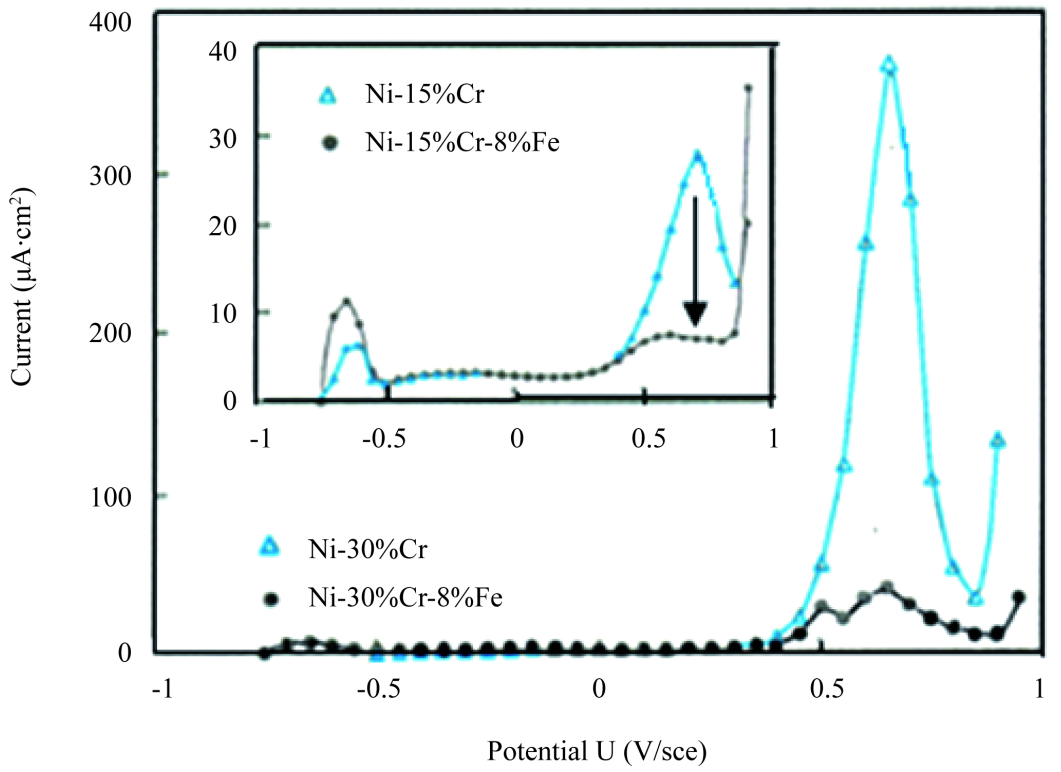

Figure 2. Potential dynamic curves of the alloys Ni-15\%Cr, Ni-15\%Cr-8\%Fe, Ni-30\%Cr, Ni-30\%Cr-8\%Fe.

The addition of chromenickel provokes an increase of the current of passivation in the high potentials area; that is to say in the region of the trans-passivation. This phenomenon linked to the dissolution of the chrome, at around $0.6 \mathrm{~V}$, is more remarkable in the case of the binary alloy $\mathrm{Ni}-30 \% \mathrm{Cr}$ where an increase of the current of passivation is very important, 10 times higher than that of the $\mathrm{Ni}-15 \% \mathrm{Cr}$.

The addition of iron (8\%) in the binary alloys $\mathrm{Ni}-15 \% \mathrm{Cr}$ and $\mathrm{Ni}-30 \% \mathrm{Cr}$ provokes an important diminution of the current of passivation in the high potentials area. This is due to the passivating character of the iron in this potential area. This result shows clearly that iron exerts a great role on the passivity of alloy 600 and 690 .

On one side, Figure 2 indicatesthat the presence of iron provokes a slight increase of the current of passivation in the negative potential area (around $-0.7 \mathrm{~V}$ ). This reflects the active behaviour of the iron in this potential area.

Finally, it appears that the increase of the current of passivation in the negative potential area due to the activation of the iron is weaker in the case of the alloys from an industry. This can be attributed to the actions of the impurities present in the industrial inconels ( $\mathrm{Si}, \mathrm{P}, \mathrm{B}, \mathrm{Mn}, \mathrm{S}, \ldots$ ). Nevertheless, the joint or specific action of this impurity remains hard to establish.

The films firstly formed in autoclave are studied in balance potential reach after 2 hours in a $\mathrm{pH} 9.2$ boric tetra borate-acid buffer solution. Values corresponding to the different oxides show that the balance potentials of the oxides formed on the inconels $600(-268 \mathrm{mV})$ and $690(-269 \mathrm{mV})$ are on the one hand identical and on the other hand electronegative. 


\subsection{Impedance Measurement}

In order to obtain the appropriate information on the effect of the frequency and the capacity in a big domain of frequency, an investigation by impedance measurement has been led on the passive films formed at different potentials. The domain of study in frequency should be largeenough (from $10^{5} \mathrm{~Hz}$ to $10^{-3} \mathrm{~Hz}$ ) in order to get to the resistances of the solution and the polarization respectively at high and low frequency. Let us note that in this case, the measurements are made at fixed potential; potential of the formation of the film.

The Bode representation presents a linear variation in a large domain of frequency $\left(10^{3} \mathrm{~Hz} ; 10^{-3} \mathrm{~Hz}\right)$. At high frequencies $\left(10^{5} \mathrm{~Hz} ; 10^{3} \mathrm{~Hz}\right)$, the impedance remains constant and equal to the resistance of the solution Rs which is about $40 \Omega \cdot \mathrm{cm}^{2}$ as shown in Figure 3. In the case of alloy 690, richer in chrome, the phenomenon happens from $0.7 \mathrm{~V}$. This shows that the linear behaviour is also controlled by the chemical composition. In fact the increase of the current at high potential due to the dissolution of the chrome around $0.6 \mathrm{~V}$; contributes enormously to the value of the impedance. In the case of the films formed to the potentials where the linearity in Bode representation is verified in a big domain of frequency, the resistance, the real part of the impedance and the capacity are linked to the frequency by expressions (1) and (2).

$$
R=R_{\text {sol }}+\frac{a}{F}+\frac{b}{F^{2}}
$$

The order of size of these parameters $a\left(10^{3}\right)$ and $b(10)$ shows that the third term of the expression (1) only becomes important at very low frequencies.

$$
\frac{1}{C}=\frac{1}{C_{0}}+P \log F
$$

where $C_{0}$ is the capacity to $F=1 \mathrm{~Hz}$ and $\mathrm{P}$ (slope) a parameter characterizing more or less the big dispersion in frequency.

Dependence in frequency of capacity and resistance has been observed in different works [6]-[15] and many causes have been proposed such as the non-uniform distribution of the current, the state and rigidity of the surface, the residual faradic processes, and so on and so forth... The linear variation between the resistance and the reverse of the frequency; $R=f(1 / F)$ and the reverse capacity and $\log F ; C=f(1 / \log F)$ have been observed in the different works concerning the dispersion in frequency of the passive films and oxides [6]-[15]. In order to provide chemical and physical explanation to these mathematical variations, many interpretations have been put forward. Van Geel [14] suggested that this is due to the film variable conductivity because of its non stoechiometry. In harmony with this hypothesis Young [11] proposed a model where the film can be represented by an electrical circuit composed of infinite RC elementary circuits parallel in series with an exponential variation of the resistivity in relation to the distance through the film. This hypothesis has also been proposed by Wood and

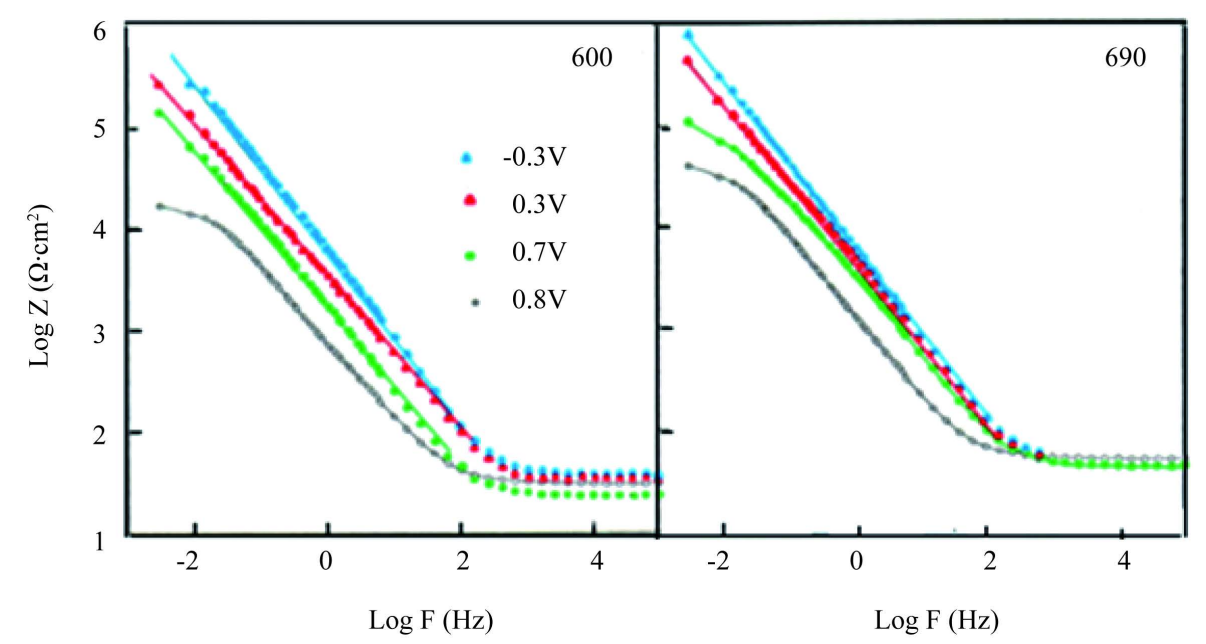

Figure 3. Bode representation of passive films formed on the inconels 600 and 690 at different potentials. 
Pearson [8] for the interpretation of the dependence infrequency of the conductivity of the anodic oxides films. From another point of view, Gomes and all [16]-[25] interpreted the linear variations on the basis of the dielectric relaxation phenomena in the film due to the contribution of the dipoles in the double stratum. The relations $\mathrm{R}(1 / \mathrm{F})$ and $1 / \mathrm{C}(\log \mathrm{F})$ have been obtained by an extension of the Gevers model [26] [27] where the dielectric constant is not real but rather complex $\left(\varepsilon=\varepsilon^{\prime}-j \varepsilon^{\prime \prime}\right)$. They have shown that the linear variation of the resistance as related to the reverse of the function $R=f(1 / F)$ can be deduced from the one that links 1/C and Log F from Kramers-Kronig relations [17] [18]. The dispersion in frequency observed in this study can be interpreted on the basis of the Young model considering a variation of the resistivity of the film in relation to its thickness. This interpretation is easily justified by the fact that the films formed on inconels are composed of different oxides that have different resistances. In this model, Young considers a circuit composed of infinite RC elementary circuits parallel in series and neglects the variation of the dielectric constant according to the frequency. The exponential variation of the resistivity in relation to the thickness of the film is expressed as follows:

$$
R=\frac{k}{4 \varepsilon \varepsilon_{0} S} \frac{1}{F}
$$

The total C capacity is given by the relation:

$$
\frac{1}{C}=\frac{k}{\varepsilon \varepsilon_{0} S} \log \left[2 \pi 2 \pi \varepsilon \varepsilon_{0} \rho(d)\right]+\frac{k}{\varepsilon \varepsilon_{0} S} \log F
$$

The comparison of Equations (3) and (4) with those already established (1) and (2) allow an identification of the parameters $(a),(P)$ and $1 / C_{0}$.

$$
a=\frac{k}{4 \varepsilon \varepsilon_{0} S} \quad P=\frac{k}{\varepsilon \varepsilon_{0} S} \frac{1}{C_{0}}=\frac{k}{\varepsilon \varepsilon_{0} S} \log \left[2 \pi 2 \pi \varepsilon \varepsilon_{0} \rho(d)\right]
$$

We remark that the ratio of slopes $(a)$ and $(P)$ is constant and equals 4 and 9.2 in decimal logarithm representation.

Thus, linear changes in the resistance obtained in the high frequency domain in the case of formed passive films are in conformity with the relationships established by Young. However curvilinear variations obtained in the field of very low frequencies have never been observed before. Because most of the work on the frequency dispersion has been limited to the field of high and medium frequencies where the variation of the resistance as a function of the reverse of the frequency is checked, curvilinear variations at very low frequencies may be due either to a change in dielectric constant as a function of the assumed zero frequency at high frequencies: Model Young, or to the slow response of deep loads under a very low frequency alternating excitation potential.

\subsection{Measurement of Capacity and Resistance}

Capacity measurements carried out at $1580 \mathrm{~Hz}$ frequency on the films formed on the alloys 600 and 690 at $0.3 \mathrm{~V}$, are represented in Figure 4.

This capacities are representative either of an electronically semi-conductor behaviour relating to a type $\mathrm{P}$ conductor (negative slopes) [28]. Figure 4, where we represented $C^{-2}$ in relation to $U$ potential, shows that the action of chromium is revealed by the appearance of a capacitive peak located in the area of the more negative potentials and characteristic of a semi-conductivity of $P$ type.

The action of iron on the capacitive behaviour of nickel is exerted, contrary to that of chromium, in the more positive potential area (Figure 5) where iron manifests a semi-conductivity of $n$ type. We observe that alloy $\mathrm{Ni}-8 \% \mathrm{Fe}$ enables the transition between the capacitive behaviour of nickel and that of iron. However the simultaneous addition of iron and chromium seems to be indispensable to the development of a passivation film capable of manifesting both types of semi-conductivity ( $\mathrm{n}$ and $\mathrm{p}$ ). So the results obtained by the study carried out on the ternary alloys $\mathrm{Ni}-15 \% \mathrm{Cr}-8 \% \mathrm{Fe}$ and $\mathrm{Ni}-30 \% \mathrm{Cr}-8 \% \mathrm{Fe}$, represent respectively the high purity versions of 600 and 690 alloys and reveal a behavior similar to that of the films formed from those of industrial origin (Figure 4). The purity factor that differentiates the two materials appeared to have little effect on the behaviour of the films.

Knowledge of the resistance values and the reverse of the fixed frequency capacity can establish a comparative investigation of the resistive and capacitive properties of passive films in relation to their potential for the 


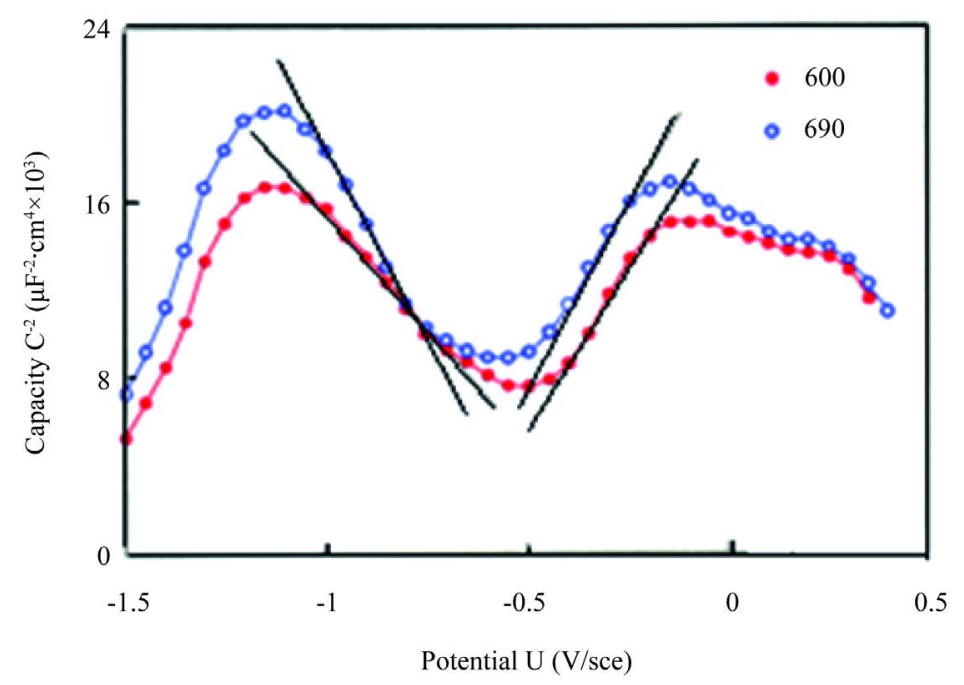

Figure 4. $C^{-2}$ as related to $\mathrm{U}$ potential in the case of passive films on alloys 600 and 690.

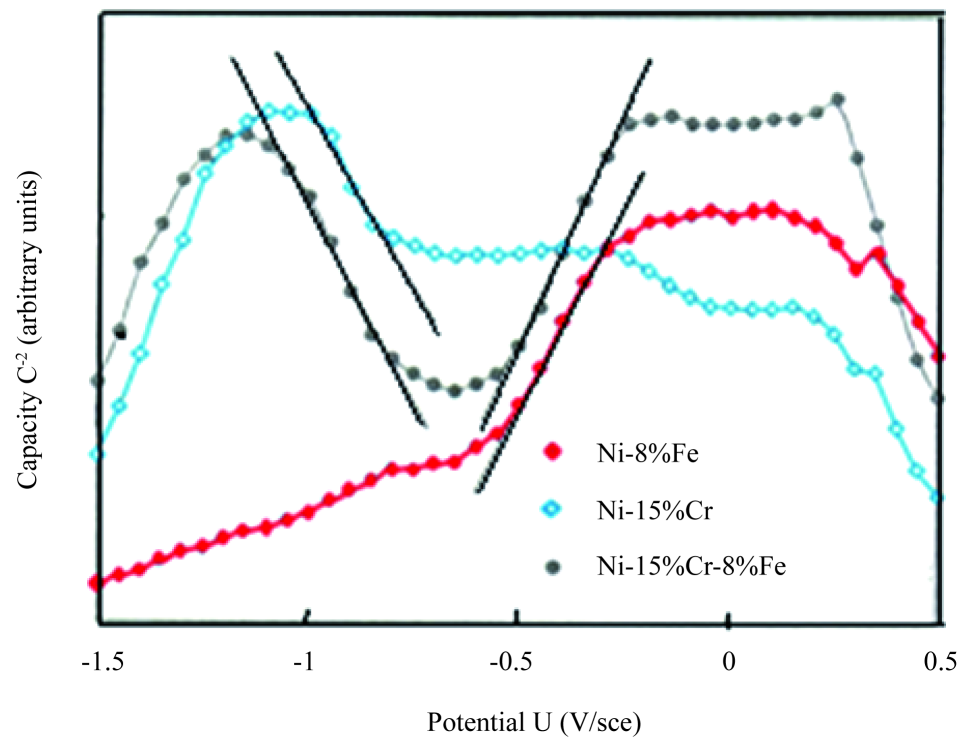

Figure 5. $C^{-2}$ in relation to $U$ potential in the case of passive films on alloys $\mathrm{Ni}-8 \% \mathrm{Fe}, \mathrm{Ni}-15 \% \mathrm{Cr}$ and $\mathrm{Ni}-15 \mathrm{Cr}-8 \% \mathrm{Fe}$.

formation and chemical composition. The choice of frequency is important for this investigation because it is necessary to pick out the values of resistance of very low frequency. This provides access to a more representative resistance of the film; it is sometimes called polarization resistance when related to corrosion. As regard capacity, the comparative study can be made on the basis of $1 / C_{0}$ values.

The representation $\mathrm{R}$ to $10^{-2} \mathrm{~Hz}$ and $1 / C_{0}$ as related to the potential of formation in the case of the films formed on the 600 and 690 alloys and the pure nickel (Figure 6) shows that the variations R and C are very similar to those of nickel indicating that the external stratum formed on the three materials are very close.

The decreasing of $\mathrm{R}$ and $\mathrm{C}$ as related to the increasing of the potential of formation becomes much accentuated from $0,6 \mathrm{~V}$ whatever the material is. The resistance as well as the reverse of the registered capacity in the case of the alloy 690 is more important than those of alloy 600 and nickel.

The photo electrochemical behavior of passive films is largely influenced by their semiconducting properties, therefore, studying photocurrent helps to better understand their electronic structure. 


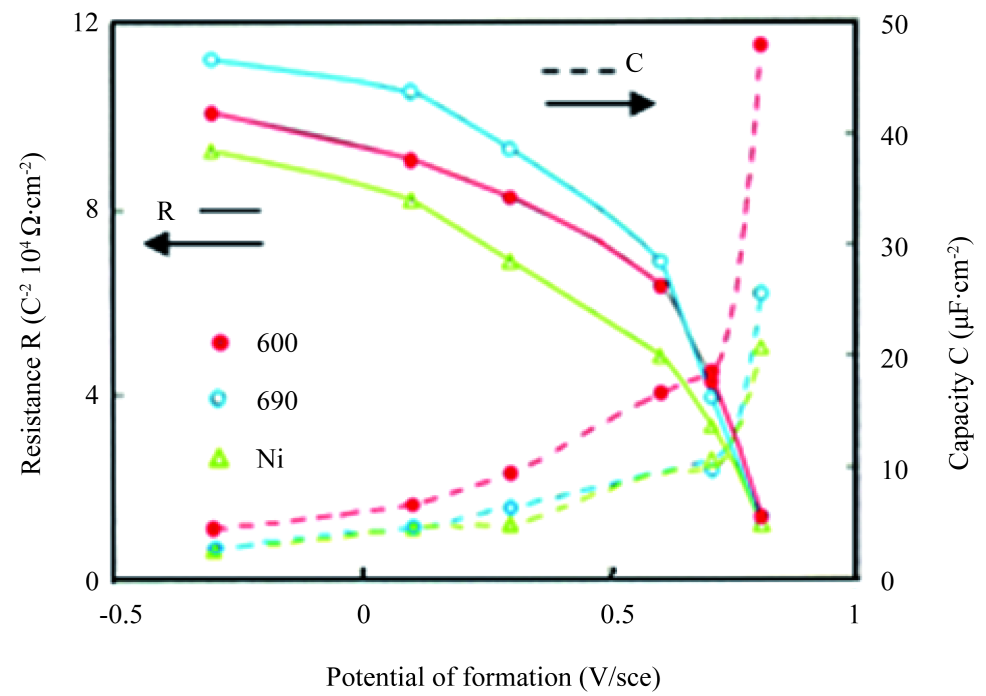

Figure 6. Variation of $\mathrm{C}$ capacity to $1580 \mathrm{~Hz}$ and $\mathrm{R}$ resistance in function of the potential of formation of the passive films formed on the inconels 600,690 and the nickel.

\subsection{Photocurrent Measurement}

Photocurrent measurement in relation to the length of the wave determines the nature of fundamental transitions, the energy of "gap" $E_{g}$ and to study the optical behaviour of the passive film close to the edge of the absorption.

The photo-electrochemical responses obtained from the potential of balance on the thick oxides films formed in autoclave are represented in Figure 7.

We remark that the photo response of alloy 600 is relatively higher than that of alloy 690. These results are of course in perfect accordance with the fact that the chemical composition of the films that develop on alloys 600 and 690 differs deeply. The films formed on alloy 690 contain more chromium oxide. For the nickel-based alloys, the gap values of the different oxides obtained by applying Equation (6) are clearly different. The determination of the energy of the gap $E_{g}$ (forbidden band) supposes the knowledge of the relation interpreting the variation of the photocurrent in relation to incidental energy $h v$. The quasi-linear variations obtained on the different passive films (Figure 7) show that the photo-electrochemical behaviour of the latter can be described by the model of Gartner [29]. In this photocurrent conditions, $I_{p h}$ is linked to the incidental energy $h v$ by the relation (6):

$$
I_{p h}=e \Phi_{0} A W \frac{\left(h v-E_{g}\right)^{n}}{h v}
$$

where $e$ represents the elementary charge, $\Phi_{0}$ the flux of photons incidents and $W$ the thickness of the zone of space charge. The Gartner model admits that the photocurrent is generated only in the zone of space charges, beyond this region the pairs of electron-pit formed recombine. Consequently only a very thick region is necessary for the photo-electrochemical effect to be possible. The analysis of the experimental results through Equation (6) allows us to reach the value of the energy of gap $E_{g}$ and the nature of $(n)$ transitions .The most precise method is the one that introduces the notion of quantic output $\eta$ defined as the ratio between the numbers of photo charges created and the number of received photons. In this condition Equation (6) becomes:

$$
\eta=\frac{I_{p h}}{\Phi_{0}}=e A W \frac{\left(h v-E_{g}\right)^{n}}{h v}
$$

The obtained results show that the value of $n$ verified experimentally $(n=2)$ is representative of indirect transitions. This is in harmony with the different works made on the stainless steel [30]-[35] and iron [6].

The values of the energy gap determined for the two alloys are substantially identical 600 (2.19 V) and 690 $(2.25 \mathrm{~V})$. 
The analysis of the region at the edge of the gap shows the presence of an Urbach [35] queue. It is an exponential variation (Figure 7).

The photocurrents measured on alloys 600 and 690 represented in Figure 8 show also two distinct regions with a quantitative difference on the global photocurrent. The existence of these two regions shows up the photo-electrochemical properties of the oxides of iron and chrome.

The capacitive study developed on the pure alloys either binary or ternary permitted to point out the role of iron and chromium on the semiconducting properties of passive films on these materials.

It appears in Figure 8 that in the case of alloy 690, the weak potential photo-electrochemical response is much more important than the one obtained at high potential whereas it is the reverse situation that appears concerning alloy 600 .

These results show in fact that the photo-electrochemical responses are well controlled by the biggest or weakest quantity of oxides of iron and chrome which constitute passive films. Moreover, the moving of the minimum toward the more negative potentials, where the potential of flat band of iron oxide is located, in the case of the alloy 600 can be attributed to the fact that the oxide formed on the latter is richer in iron oxide than the one formed on alloy 690 .

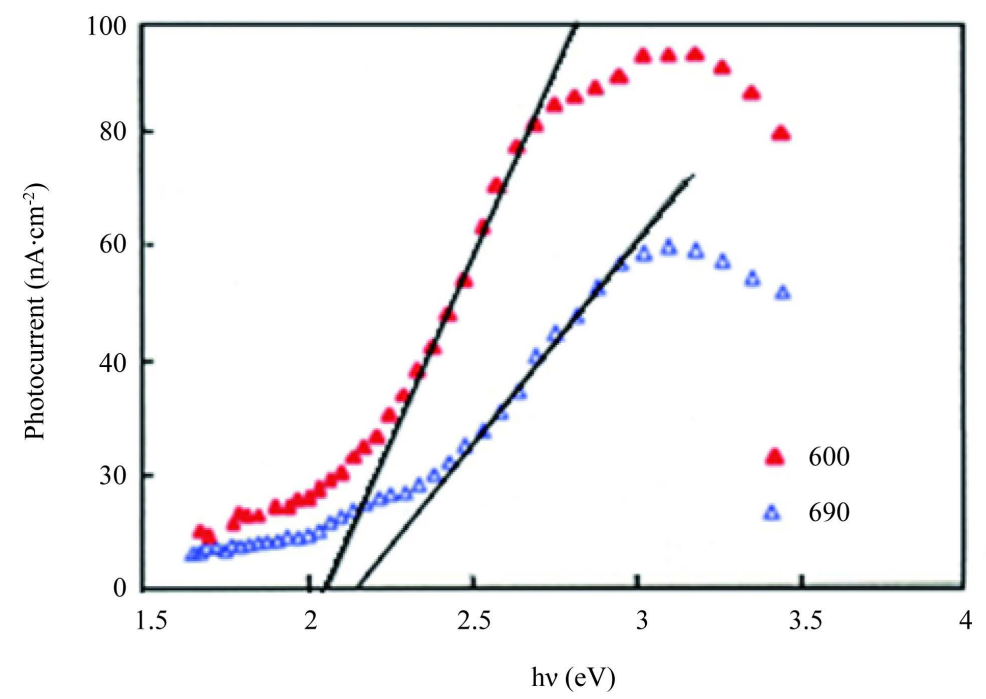

Figure 7. Photocurrent related to incidental energy in the case of the films formed on the inconels 600 and 690 .

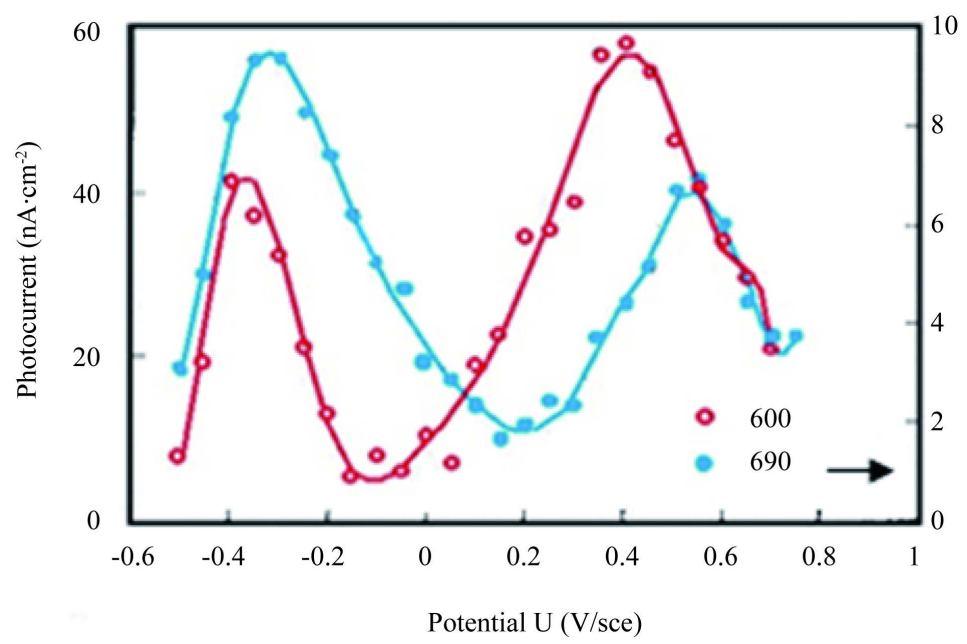

Figure 8. Photocurrent related to U potential. 


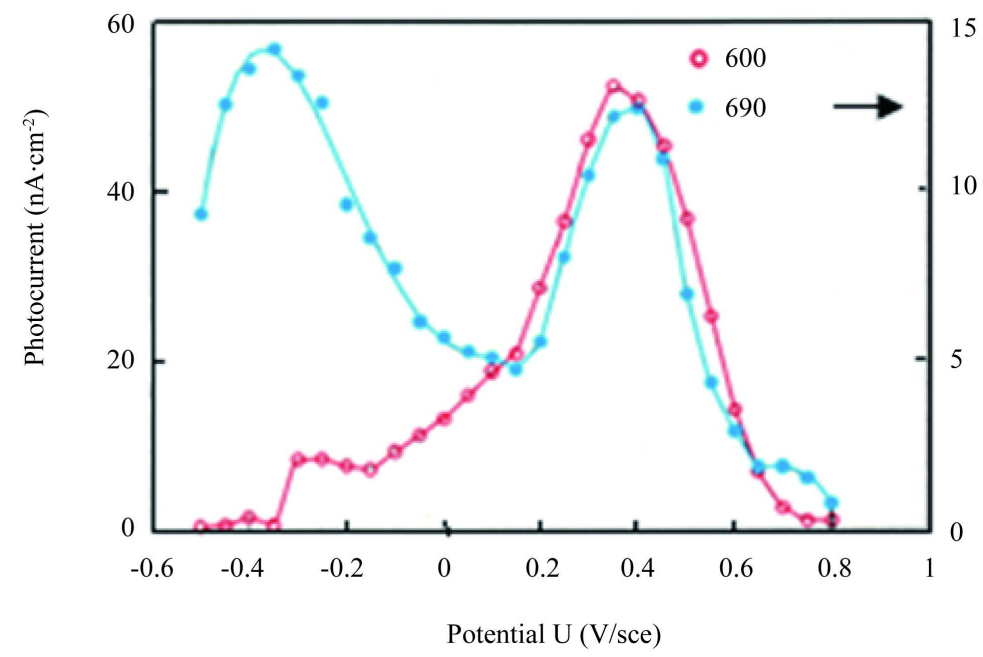

Figure 9. Photocurrent in relation to the applied in the case of films formed on the inconels potential $\mathrm{U}$ in the case of the films 600 and 690 at $0.6 \mathrm{~V}$. formed on the inconels 600 and 690 exposed $2000 \mathrm{H}$ in primary area.

The results obtained on the oxide films formed on both types of alloy are represented in Figure 9 where we remark that in relation to the applied potential, the photo current representation in the case of inconel 690 reveals also the existence of two regions separated by a potential of about $0 \mathrm{~V}$ and characterized by the peak of amplitude of about $0.4 \mathrm{~V}$. These variations are similar to those obtained by measurement of capacity. The absence of the second region at low potential in the case of the oxide formed on inconel 600 already obtained by measurement of capacity confirms the fact that this oxide is on a chemical point of view very rich in oxide of iron.

\section{Conclusions}

The use of a great number of techniques has made possible the characterization of passive films formed on inconels. This has permitted to establish precise relations between the chemical compositions of the passive films formed on the inconels.

As far as chemical composition is concerned, the passive films formed on the inconels consist of two regions. The passive oxide formed on alloy 600 is richer in oxide of iron than that one formed on alloy 690. The response of the photocurrent in the case of Inconel 690 also reveals the existence of two regions separated by a potential of about $0 \mathrm{~V}$ and characterized by the peak of amplitude of about $0.4 \mathrm{~V}$.

The absence of the second region at low potential in the case of the oxide formed on the inconel 600 already obtained by measurement of capacity confirms the fact that this oxide is very rich in oxide of iron on the chemical area.

The nature of the films is deeply linked to the chemical composition of the alloy. For the case of the Inconel $600(15 \% \mathrm{Cr})$, both regions of the duplex have practically the same thickness.

Iron oxide is the principal component in surface. The capacitive results obtained at different frequencies reveal equally the existence of two regions. The photocurrents measured on alloy 600 also show two distinct regions with a quantitative difference on the global photocurrent. The existence of these two regions proves the photo-electrochemical properties of iron and chromium oxides.

\section{References}

[1] Simoes, A.M.P., Ferreira M.G.S., Rondot B. and Da Cunha Belo, M. (1990) Study of Passive Formed on AISI 304 Stainless Steel by Impedance Measurements and Photoelectrochemistry. Journal of the Electrochemical Society, 137, 82-87. http://dx.doi.org/10.1149/1.2086444

[2] Di Paola, A. (1989) Semiconducting Proprieties of Passive Films on Stainless Steels. Electrochimica Acta, 34, 203210. http://dx.doi.org/10.1016/0013-4686(89)87086-0

[3] Burlrigh, T.D. and Latanision, R.M. (1987) The Use of Photocurrents to Characterize Anodic Films on Ti, Zr, Cu, and 
304 Stainless Steel. Journal of the Electrochemical Society, 134, 135-138. http://dx.doi.org/10.1149/1.2100391

[4] Ferreira, M.G.S. and Dawson, J.L. (1985) Electrochemical Studies of the Passive Film on 316 Stainless Steel in Chloride Media. Journal of the Electrochemical Society, 132, 760-765. http://dx.doi.org/10.1149/1.2113954

[5] Harrison, J.A. and Williams, D.E. (1986) How Does the Electrochemical Behaviour of Stainless Steel Reflect That of Its Constituent Elements. Electrochimica Acta, 31, 1063-1072. http://dx.doi.org/10.1016/0013-4686(86)80021-4

[6] Heusler, K.E. and Schulze, M. (1975) Electron-Transfer Reactions at Semiconducting Anodic Niobium Oxide Films. Electrochimica Acta, 20, 237-244. http://dx.doi.org/10.1016/0013-4686(75)85031-6

[7] Heusler, K.E. and Yun, K.S. (1977) Electron Transfer Reactions at Film Covered Metal Electrodes. Electrochimica Acta, 22, 977-986. http://dx.doi.org/10.1016/0013-4686(77)85009-3

[8] Harrop, P.J., Wood, G.C. and Pearson, C. (1968) AC Conduction in Amorphous Films. Thin Solid Films, 2, 457-466. http://dx.doi.org/10.1016/0040-6090(68)90059-X

[9] Hakiki, N.B., Boudin, S., Rondot, B. and Belo, M.D.C. (1995) The Electronic Structure of Passive Films Formed on Stainless Steels. Corrosion Science, 37, 1809-1822. http://dx.doi.org/10.1016/0010-938X(95)00084-W

[10] Van Der Ziel, A. (1950) On the Noise Spectra of Semi-Conductor Noise and of Flicker Effect. Physica, 16, 359-372. http://dx.doi.org/10.1016/0031-8914(50)90078-4

[11] Young, L. (1957) Anomalies in the Growth of Anodic Oxide Films on Rough Surfaces. Acta Metallurgica, 5, 711-716. http://dx.doi.org/10.1016/0001-6160(57)90073-1

[12] Kasilingam, A.R., Balasubramanian, C. and Radhakrishnan, M. (1980) Frequency Characteristics of Thermally Evaporated Stearic Acid Films. Physica Status Solidi (a), 57, 35-39.

[13] Kapusta, S. and Hackerman, N. (1980) Capacitive Studies of the Semiconducting Properties of Passive Tin Electrodes. Electrochimica Acta, 25, 949-955. http://dx.doi.org/10.1016/0013-4686(80)87099-X

[14] Nikolov, T., Aroyo, M., Klein, E. and Ikonopisov, S. (1975) Impedance and Frequency Characteristics of Anodic $\mathrm{Bi}_{2} \mathrm{O}_{3}$ Films. Thin Solid Films, 30, 37-46. http://dx.doi.org/10.1016/0040-6090(75)90302-8

[15] Montemor, M.F., Ferreira, M.G.S., Hakiki, N.E. and Belo, M.D.C. (2000) Chemical Composition and Electronic Structure of the Oxide Films Formed on 316L Stainless Steel and Nickel Based Alloys in High Temperature Aqueous Environments. Corrosion Science, 42, 1635-1650. http://dx.doi.org/10.1016/S0010-938X(00)00012-3

[16] Hamadou, L., Kadri, A. and Benbrahim, N. (2005) Characterisation of Passive Films Formed on Low Carbon Steel in Borate Buffer Solution (pH 9.2) by Electrochemical Impedance Spectroscopy. Applied Surface Science, 252, 15101519. http://dx.doi.org/10.1016/j.apsusc.2005.02.135

[17] Bojinov, M., Fabricius, G., Laitinen, T., Mäkelä, K., Saario, T. and Sundholm, G. (2000) Coupling between Ionic Defect Structure and Electronic Conduction in Passive Films on Iron, Chromium and Iron-Chromium Alloys, Electrochimica Acta, 45, 2029-2048. http://dx.doi.org/10.1016/S0013-4686(99)00423-5

[18] Randin, J.P. (1974) Alternating Current Impedance Characteristics of Reduced and Oxidised Sodium-Tungsten Bronze Electrodes. Electrochimica Acta, 19, 87-96. http://dx.doi.org/10.1016/0013-4686(74)85061-9

[19] Osozawa, K., Bohnenkamp, K. and Engell, H.J. (1966) Potentiostatic Study on the Intergranular Corrosion of an Austenitic Chromium-Nickel Stainless Steel. Corrosion Science, 6, 421-433. http://dx.doi.org/10.1016/0010-938X(66)80014-8

[20] Di Paola, A., Shukla, D. and Stimming, U. (1991) Photoelectrochemical Study of Passive Films on Stainless Steel in Neutral Solutions. Electrochimica Acta, 36, 345-352. http://dx.doi.org/10.1016/0013-4686(91)85260-E

[21] Thompson, E.A. and Burleigh, T.D. (2007) Accelerated Corrosion of Zinc Alloys Exposed to Ultraviolet Light. Corrosion Engineering, Science and Technology, 42, 237-241. http://dx.doi.org/10.1179/174327807X214581

[22] Schmuki, P. and Böhni, H. (1992) Metastable Pitting and Semiconductive Properties of Passive Films. Journal of the Electrochemical Society, 139, 1908-1913. http://dx.doi.org/10.1149/1.2069520

[23] Abreu, C.M., Cristóbal, M.J., Losada, R., Nóvoa, X.R., Pena, G. and Pérez, M.C. (2004) High Frequency Impedance Spectroscopy Study of Passive Films Formed on AISI 316 Stainless Steel in Alkaline Medium. Journal of Electroanalytical Chemistry, 572, 335-345. http://dx.doi.org/10.1016/j.jelechem.2004.01.015

[24] Babić, R. and Metikoš-Huković, M. (1993) Semiconducting Properties of Passive Films on AISI 304 and 316 Stainless Steels. Journal of Electroanalytical Chemistry, 359, 143-160. http://dx.doi.org/10.1016/0022-0728(93)80435-K

[25] Bojinov, M., Laitinen, T., Mäkelä, K. and Saario, T. (2001) Conduction Mechanism of the Passive Film on Iron Based on Contact Electric Impedance and Resistance Measurements. Journal of the Electrochemical Society, 148, 243-250. http://dx.doi.org/10.1149/1.1371976

[26] Ginley, D.S. and Butler, M.A. (1977) The Photoelectrolysis of Water Using Iron Titanate Anodes. Journal of Applied Physics, 48, 2019-2021. http://dx.doi.org/10.1063/1.323911 
[27] Stimming, U. (1986) Photoelectrochemical Studies of Passive Films. Electrochimica Acta, 31, 415-429. http://dx.doi.org/10.1016/0013-4686(86)80104-9

[28] Gassama, D., Faty, S. and Niang, F. (2010) Structure duplex des films minces formes sur des aciers inoxydables austenitiques. Journal des Sciences, 10, 47-54.

[29] Kainthla, R.C., Khan, S.U.M. and Bockris, J.M. (1987) The Theory of Electrode Matching in Photoelectrochemical Cells for the Production of Hydrogen. International Journal of Hydrogen Energy, 12, 381-392. http://dx.doi.org/10.1016/0360-3199(87)90157-1

[30] Di Castro, E.B. and Vilche, J.R. (1993) Investigation of Passive Layers on Iron and Iron-Chromium Alloys by Electrochemical Impedance Spectroscopy. Electrochimica Acta, 38, 1567-1572. http://dx.doi.org/10.1016/0013-4686(93)80291-7

[31] Okamoto, G. and Shibata, T. (1970) Stability of Passive Stainless Steel in Relation to the Potential of Passivation Treatment. Corrosion Science, 10, 371-378. http://dx.doi.org/10.1016/S0010-938X(70)80027-0

[32] Hashimoto, K., Asami, K. and Teramoto, K. (1979) An X-Ray Photo-Electron Spectroscopic Study on the Role of Molybdenum in Increasing the Corrosion Resistance of Ferritic Stainless Steels in HC1. Corrosion Science, 19, 3-14. http://dx.doi.org/10.1016/0010-938X(79)90003-9

[33] Gad Allah, A.G., Salih, S.A., Hefny, M.M. and Mogoda, A.S. (1990) Anodic Dissolution of Antimony in Phosphate Solutions. Corrosion, 46, 214-220. http://dx.doi.org/10.5006/1.3585094

[34] Patrito, E.M., Torresi, R.M., Leiva, E.P.M. and Macagno, V.A. (1990) Potentiodynamic and AC Impedance Investigation of Anodic Zirconium Oxide Films. Journal of the Electrochemical Society, 137, 524-530. http://dx.doi.org/10.1149/1.2086492

[35] Dresner, J. and Stringfellow, G.B. (1968) Electronic Processes in the Photo-Crystallization of Vitreous Selenium. Journal of Physics and Chemistry of Solids, 29, 305-311. http://dx.doi.org/10.1016/0022-3697(68)90075-9 